\title{
Recommendations on respiratory hygiene: kit of equipment and information for patients to improve their compliance
}

\author{
José Sánchez-Payá, Julio Barrenengoa Sañudo, Hector Martínez, \\ Robert Camargo Angeles, Patricia Garcia Shimizu \\ Hospital General Universitario de Alicante, Spain
}

doi: 10.3396/ijic.V6i1.009.10

We think patients with Feverish Respiratory Disease (fever and cough and/or sore throat) should be given a set of equipment and information when they contact with the Healthcare System. This should contain a pack of tissues, surgical face masks (at least two), a pocket bottle of alcoholic hand rub and an information leaflet describing respiratory hygiene $(\mathrm{RH})$ precautions. The aim is to improve compliance with $\mathrm{RH}$ by patients and companions, and reduce the transmission of infection in points of contact in healthcare centres (reception, waiting rooms etc), which was shown to be a danger in the outbreaks of Severe Acute Respiratory Distress syndrome in 2003..$^{-3}$ Since then Respiratory Hygiene has been added to Standard precautions, with the aim of ensuring that patients with suspected respiratory tract infection together with their companions practise this when entering healthcare centres. The precautions include covering the nose and mouth with a tissue when coughing or sneezing, disposing of the tissue immediately after use followed by hand hygiene, use a surgical mask (if tolerated) and staying $>1$ meter from other people. ${ }^{4}$
Our proposal works on the sources of infection, so should reduce transmission of the agents that cause Acute Respiratory infections such as the currently worrying Influenza A virus (H1N1).

Following the improvement in compliance with hand hygiene found in healthcare workers by having pocket bottles of alcoholic solutions - i.e. a 'personal' facility, ${ }^{5-6}$

one can deduce that availability of materials and information for patients will improve their compliance. Another advantage would be no need to move around to get tissues or use a communal sink for hand hygiene (a problem if the patient does not wear a mask).

This proposal has not yet been evaluated, although evaluations using current methods to monitor the degree of compliance with hand hygiene would not be difficult. Another problem is cost - (US \$2.5-3.24), which may not be supported by the managers of Health Centres.

\section{Corresponding author}

José Sánchez-Payá, Hospital General Universitario de Alicante, Spain

Email: sanchez_jos@gva.es 
In short it is logical to think that the availability of such a kit would improve compliance with Respiratory Hygiene.

\section{References}

1. Varia $M$, Wilson $S$, Sarwal $S$, et al. Investigation of a nosocomial outbreak of severe acute respiratory syndrome (SARS) in Toronto, Canada. CMJ 2003; 169: 285-292.

2. Chen Y-C, Huang L-M, Chan C-C, et al. SARS in Hospital Emergency Room. Emerg Infect Dis 2004; 10: 782-788.

3. CDC. Severe acute respiratory syndrome--Taiwan, 2003. Morb Mortal Wkly Rep 2003; 52: 461- 466.

4. Siegel JD, Rhinehart E, Jackson M, Chiarello L. Healthcare Infection Control Practices Advisory Committee. 2007 guideline for isolation precautions: preventing transmission of infectious agents in health-care settings. Atlanta, GA: US Department of Health and Human Services, CDC; 2007. Available at http://www.cdc.gov/ncidod/dhqp/gl_isolation. html.
5. Kim PW, Roghmann MC, Perencevich EN, Harris AD. Rates of hand disinfection associated with glove use, patient isolation, and changes between exposure to various body sites. Am J Infect Control 2003; 31: 97-103.

6. Simon AC. Hand hygiene, the crusade of the infection control specialist. Alcohol-based handrub: the solution! Acta Clin Belg 2004; 59: 189-193.

7. Sánchez-Payá J, Galicia-García MD, Gracia-Rodríguez RM, et al. Grado de cumplimiento y determinantes de las recomendaciones sobre la Higiene de Manos. Enferm Infecc Microbiol Clin 2007; 25: 369-375.

8. Sánchez-Payá J, Fuster-Pérez M, García-González C, et al. Evaluacion de un programa de actualización de las recomendaciones sobre la Higiene de Manos. An Sist Sanit Navar. 2007; 30: 343-352. 